\title{
Utilization of WRF 3D Meteorological Data to Calculate Slant Total Delay for InSAR Atmospheric Correction
}

\author{
Xinyi Wang ${ }^{1}$ (D) $\cdot$ Qiming Zeng ${ }^{1} \cdot$ Jian Jiao $^{1}$ \\ Received: 7 February 2020 / Revised: 6 November 2020 / Accepted: 20 November 2020 / Published online: 25 January 2021 \\ (C) The Author(s) 2021
}

\begin{abstract}
The atmosphere introduces excess delays into the synthetic aperture radar (SAR) signal trajectory, especially in the troposphere. InSAR atmospheric correction methods include the use of SAR data and external water vapor products. The latter is more effective. However, since the removal of atmospheric effects should use atmospheric delay products in the direction of the line of sight (LOS), it is necessary to convert the zenith total delay to slant delay in the LOS direction. Conventionally, the zenith delay is divided by the cosine of the average incident angles to obtain slant phase delays. But this method could cause large errors because it ignores the atmospheric horizontal gradient change and the small-scale vertical structure. These problems can be solved by using three-dimensional atmospheric data simulated by numerical models, especially in the case of intense weather changes or complex terrain. However, few scholars paid attention to the application into InSAR atmospheric correction, because of the computation complexity and low efficiency. As the requirement for higher accuracy and the introduction of large errors caused by increasing incidence angles, it is significantly imperative to make the utmost of this method. Weather Research Forecast (WRF) model can provide the precipitate water vapor (PWV) and refraction index at different levels in the three dimensions, and then the slant total delay can be obtained for removing the atmospheric effect on the InSAR process. The results demonstrate that using 3D data can obtain more accurate slant total delay and improve the accuracy of surface deformation from InSAR technology.
\end{abstract}

Keywords InSAR · Three-dimensional (3D) $\cdot$ Atmospheric correction $\cdot$ Slant delay $\cdot$ WRF

\section{Introduction}

Since synthetic aperture radar (SAR) was developed, its applications have covered many aspects such as earthquake (e.g., [1-4]), volcano (e.g., [5-7]), mine collapse (e.g., [8, 9]), resource exploration (e.g., [10]), and urban ground subsidence measurement (e.g., [11-14]). All of these applications refer to surface deformation, which is difficult to be measured especially for subtle changes. In terms of the factors affecting the surface deformation accuracy, the atmospheric effect on the SAR signal is considerable, in particular, the water vapor [15]. Zebker et al. demonstrated that $20 \%$ spatiotemporal changes of relative humidity in the atmosphere could cause the 10-14 $\mathrm{cm}$ surface deformation [16]. And the effect of the

Qiming Zeng

qmzeng@pku.edu.cn

1 Institute of Remote Sensing and Geographical Information System, Peking University, Beijing 100871, China uncertainty of $1.0 \mathrm{~mm}$ atmospheric precipitable water vapor (PWV) on the standard deviation of Interferometric SAR (InSAR) surface deformation in the direction of line-of-sight (LOS) is about $15 \mathrm{~mm}$ [17]. Besides this wet delay caused by the precipitable water vapor, the hydrostatic delay related to the dry air and hydrostatic pressure accounts for about $15 \%$ of the total delay, and so it is not negligible [18]. Therefore, eliminating the atmospheric effect on the InSAR results is an important and challenging issue for high-precision InSAR measurement and application. Therefore, spatiotemporal variations of the atmosphere especially the troposphere have a significant impact on InSAR accurate geodetic applications.

To quantify the effects and achieve InSAR atmospheric correction, many researchers introduced external water vapor datasets from MEdium Resolution Imaging Spectrometer (MERIS) ([19-21]), MODerate resolution Imaging Spectroradiometer (MODIS) ([19, 21] Global Positioning System (GPS) stations ([22-24]), and numerical weather models (NWMs) (e.g., [6, 18, 25, 26]). Among them, NWMs are more feasible and potential, including the ERAInterim from the European Centre for Medium-Range 
Weather Forecasts (ECMWF) [25, 27], the mesoscale analysis model from the Japanese Meteorologic Agency (MANAL) [28], Fifth-Generation PSU/NCAR Mesoscale Model (MM5) $([18,29,30])$, and Weather Research\& Forecast (WRF) model [6, 26, 31-33]. However, these data are not along the SAR signal trajectory (except the advanced synthetic aperture radar (ASAR) and MERIS), and there exists a degree difference between the direction of these data and that of the SAR signal. Therefore, a corrective scheme is applied to transform vertically integrated delay into the slant direction (i.e., the SAR signal trajectory between the satellite and the ground) by dividing the cosine of the mean incidence angle. This simplified scheme could be reliable and applicable when the incidence angles of the SAR satellites are small enough (e.g., less than $32^{\circ}$ according to Li [34]) or close to elevation angels [28].

However, atmospheric conditions in zenith and slant direction can vary significantly even over small scales, and if atmospheric noise is comparable to the geophysical signals in the spatial or temporal domains, the simplification method would not work well and can easily evoke errors. Therefore, some mapping functions, including empirical slant delay models and other improved models, are proposed to process observations from radio space geodetic techniques. Boehm et al. proposed the Global Mapping Function (GMF) model based on the ECMWF numerical weather model and demonstrated that their regional height biases and annual errors were significantly reduced with GMF instead of the Niell Mapping Function (NMF). GMF's coefficients were obtained from an expansion of the Vienna Mapping Function (VMF1) parameters into spherical harmonics on a global grid. Similarly, Lagler et al. showed that their Global Pressure and Temperature 2 (GPT2) could yield a $40 \%$ reduction of annual and semi-annual amplitude differences in station heights, overcoming the weakness of the GMF and VMF1, limited spatial, and temporal variability [35]. And Yuan et al. proposed the forecast VMF1 (VMF1-FC) model based on the ECMWF data and showed that VMF1-FC performs better than empirical models such as GPT2 [36]. However, all of these mapping functions are widely utilized in real-time GPS, Global Navigation Satellite System (GNSS), and Very-Long-Baseline Interferometry (VLBI) applications, not in the InSAR measurement due to their short wavelength. But Hobiger et al. applied their mapping function into the InSAR measurement. According to Hobiger [28, 37], changes of wet refractivity or temperature in different height and horizontal direction introduce millimeter order biases when the simplified method is applied instead of their exact raytracing method. They concluded that their ray-tracing approach differed from the simple mapping strategy by up to $10 \mathrm{~mm}$ and had a crucial impact on improving the interpretation of ground motion obtained from InSAR.

However, in recent years, no scholars utilized this threedimensional (3D) ray-tracing approach or other mapping functions to model the atmospheric total delay and achieve the prevailing InSAR atmospheric correction. The reasons could be as follows. Firstly, it is the complex and timeconsuming computation that prevents this method from general application in InSAR technology. Secondly, considering the interdisciplinary research between meteorology and satellite science, it remains a challenge to obtain the 3D atmospheric parameters and calculate the wet delay and hydrostatic delay. Thirdly, Hobiger et al. tried to study the effects from a single profile to find whether ray-tracing for the InSAR correction is necessary. A single profile could evoke errors because of jump-like changes of wet refractivity among voxels of a SAR image [28]. Last but not least, the incidence angles of most satellites were less than $40^{\circ}$, not true for Sentinel, ALOS-2, and so on. The details of the prevailing incidence angles of SAR satellites are shown in the Appendix, Table 3. Therefore, due to the major impact on improving the accuracy of the reconstructed atmospheric delay, it would be imperative and significant to make further research about obtaining more precise 3D atmospheric data and applying them into general InSAR correction. And then, a faster and powerful tool to calculate the atmospheric delay for InSAR would be a better option for SAR scholars. Zhu et al. also noticed this problem and proposed a method that the troposphere is divided into three vertical layers and determined the weights of all pixels on each layer to obtain the Zenith Path Delay Difference Map (ZPDDM). They perceived that their method considered the atmospheric turbulence and heterogeneity and could improve the InSAR results compared with the conventional approach in the Beijing area. However, MERIS products are easily contaminated by the cloud. Besides, there are only three vertical layers, and actually, they projected the ZPDDM into the slant total delay (SLD) along the LOS direction by dividing by the cosine of the radar incidence angle. Despite these limitations, the great significance and necessity have attracted the attention of many scholars.

As numerical weather models are continuously improving their spatial resolution and updating the topographical and land cover datasets, it becomes more and more attainable to replace the simplification scheme with $3 \mathrm{D}$ atmospheric data to obtain a more accurate total delay along the SAR signal trajectory. In this study, we present that WRF simulates 3D atmospheric parameters including pressure, temperature, and water vapor mixing ratio and calculates the atmospheric delays at the acquisition time of the InSAR images along the SAR signal trajectory, which are then applied to eliminating atmospheric effects on the D-InSAR process.

This problem deserves specified and further research and description. What is more, it remains a problem whether and when one has to use the 3D meteorological tropospheric delay to avoid evoking errors considering the specific threshold or range of incidence angles. To solve this problem, different incidence angles are modeled according to the current 
satellites (see the Appendix), ranging from 10 to $60^{\circ}$, and calculated the errors caused by the difference between the local incidence angles and mean incidence angles.

The paper is constructed as follows: the second part will introduce the atmospheric anisotropy from its horizontal and vertical direction. And then, the principles of calculating the 3D total delay along the SAR signal path are described in the third part, followed by the results and discussion in the fourth part. Last, it is the conclusions.

\section{Atmospheric Anisotropy Analysis}

In the process of InSAR atmospheric correction, concerning the simplification method, the propagation trajectory is regarded as a straight line. However, due to the anisotropy of the atmosphere and refraction effect, the meteorological parameters change in the horizontal and vertical direction, especially under the situation of extreme weather. The refraction calculation should be performed on each pixel of the SAR images theoretically, which is relatively cumbersome and difficult. Hence, we propose to use short lines (see orange lines in Fig. 1) to calculate the delay, as Snell's law can be extended to the atmosphere in which the refractive index changes continuously with the height. Assuming that the atmosphere is spherically layered, the refractive index changes only with height, and the atmosphere is divided into layers of concentric spherical layers. The refractive index in each layer is constant. Propagating along a straight line in each layer and refraction at each interface (see Fig. 1), the line segment trajectory equation in this spherically layered atmosphere can be derived: $\mathrm{n} \times$ $\cos \theta=$ constent. Therefore, it is reasonable and attainable to utilize this polyline to achieve the calculation of the slant delay instead of voxels integration.

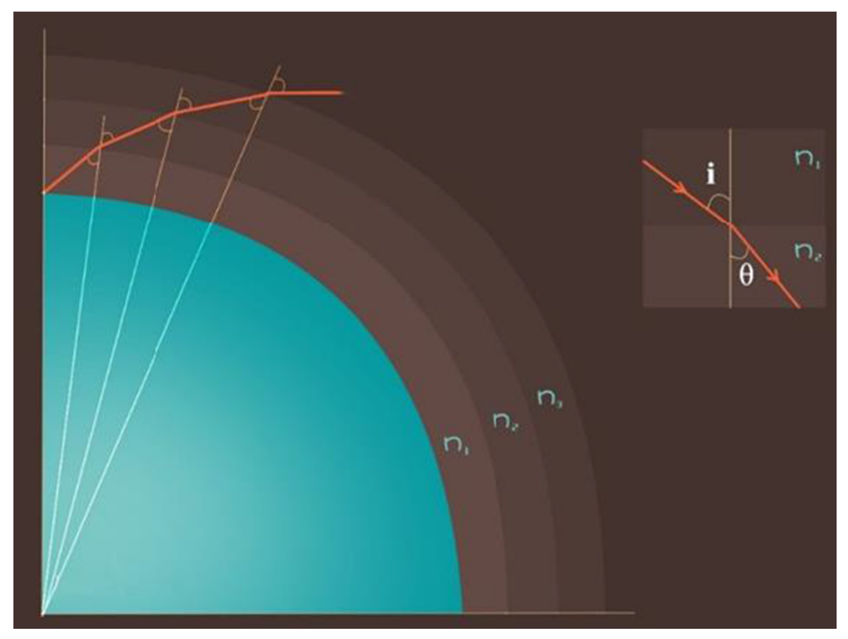

Fig. 1 Sketch map of the atmospheric refraction effect
Figure 2a shows the atmospheric pressure has a similar tendency to the refraction index. What is more, the difference is noticeable in horizontal direction especially near the surface with big gradients about a maximum value of $5 \mathrm{kPa}$ within $5 \mathrm{~km}$. Figure $2 \mathrm{~b}$ illuminates more considerable differences in the parallel (see purple lines). The values in the green line are different from those in the red line, with a maximum value of $10 \mathrm{~mm}$ on the 12th level. The lateral gradients are too big to be neglected. Using the green line instead of the red line would inevitably evoke great errors in the calculation of the total delay, particularly in the bottom levels.

As for the vertical variations, as the altitude increases, the atmospheric pressure that affects the static delay of atmospheric fluid changes with height. As shown in Fig. 2a, it can be seen that when the height reaches 23 layers (corresponding to a height of $15 \mathrm{~km}$ ), the atmospheric pressure intensity changes slowly. Similarly, the atmospheric humidity delay changes (Fig. 2b). It is getting smaller and smaller. At the height of the 16th level (about $10 \mathrm{~km}$ ), the atmospheric wet delay is no longer change and less than $2 \mathrm{~mm}$. The standard deviation (std) of zenith total delay (ZTD) in each layer is shown in Fig. 3. As we can see, if the accuracy of $2 \mathrm{~mm}$ is required, setting the number of layers to 20 can meet the requirement. Therefore, the model setting layer does not need too much, and the elevation setting can be reduced to the atmospheric troposphere range accordingly.

\section{Method and Implementation}

\subsection{The Calculation of Atmospheric Phase Delay}

Atmospheric refractivity $N$ is computed by Eq. (1) as follows as demonstrated by Smith and Weintraub [38].

$N=(n-1) \cdot 10^{-6}=k_{1} \frac{P_{h}}{T}+k_{2} \frac{P_{w}}{T}+k_{3} \frac{P_{w}}{T^{2}}$

where $P_{h}$ and $P_{w}$ are the partial pressures of the hydrostatic air and water vapor in $\mathrm{hPa}$, respectively, and $T$ is the absolute temperature. $k_{1}=77.604 \mathrm{KhPa}^{-1}, k_{2}=70.4 \mathrm{KhPa}^{-1}, k_{3}=$ $373.900 \mathrm{~K}^{2} \mathrm{hPa}^{-1}$ according to Bevis et al. [39].

Snell's law can be used to calculate the relationship between the refractive index and angles of incidence and refraction when the SAR signal goes through the different density of the atmosphere boundary. On the boundary line between different layers, it is necessary to calculate the refraction effect by Eq. (2). We calculate $n_{k}$ at different levels according to formula (1) and then calculated the apparent zenith angle $\theta_{k}$ by Snell's law (see Formulas (2) and (3)).

$\sin \theta_{k}=\frac{\sin \alpha_{k}}{n_{k}} \times n_{k-1}$ 


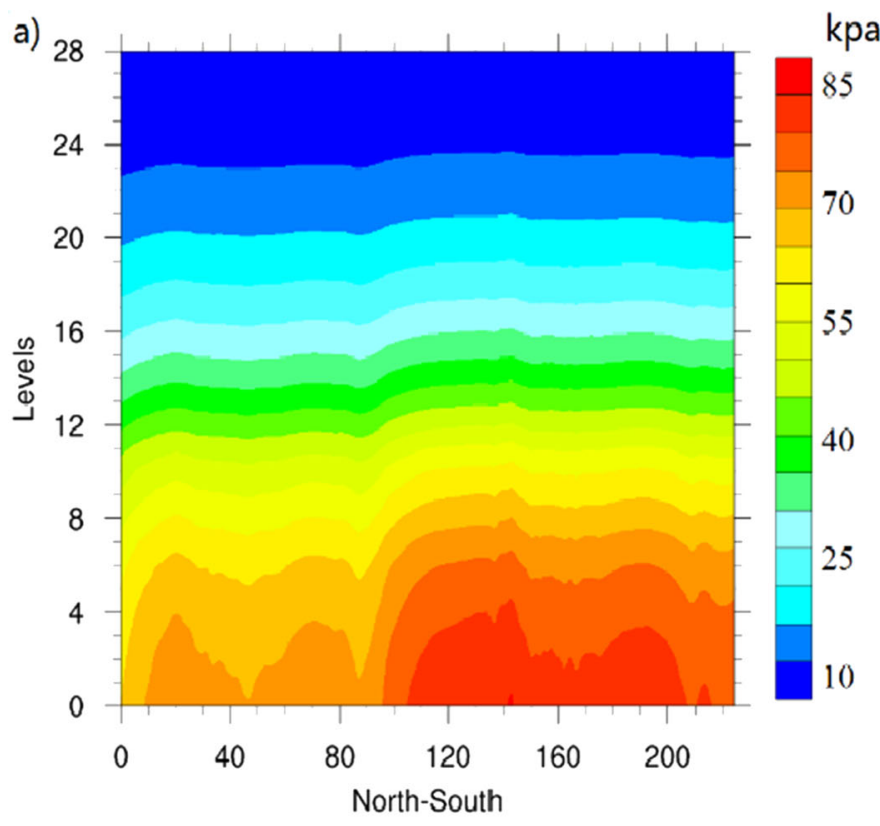

Fig. 2 Pressure (a) and slant wet delay (b) change in the middle profile with the height. In $\mathbf{b}$, the red vertical line represents the zenith phase delay, and the green slant line shows the slant delay obtained from ZTD dividing the mean incidence angle; the red polyline shows the

$\cos \theta_{k}=\sqrt{1-\sin ^{2} \theta_{k}}$

With respect to atmospheric parameters, the 3D fields of the temperature, atmospheric pressure, water vapor mixing ratio, geopotential, and hydrostatic pressure can be obtained from WRF, and PWV at the acquisition times of SAR images can be calculated by Eq. (4) as follows:

$\mathrm{PWV}_{k}=\frac{1}{\rho_{\text {water }}} \frac{P_{k}}{R_{d} T_{v k}} Q_{\text {vapor }}^{k} \times \Delta z$

where $\rho_{\text {water }}$ is the water density, $k$ is the vertical layer, and $R_{d}=287.0583 \mathrm{~J} /(\mathrm{K} \cdot \mathrm{kg}) . P_{k}$ is the atmospheric pressure, $T_{v k}$ is the virtual temperature, $Q_{\mathrm{vapor}}^{k}$ is the water vapor mixing ratio, and $\Delta z$ is the total geopotential height in the $k$ th layer, less than $700 \mathrm{~m}$. Then, the zenith wet delay $\left(L_{\mathrm{ZWD}}\right)$ can be calculated by Eq. (5). And the $\Pi^{-1}$ is calculated by Eq. (6).

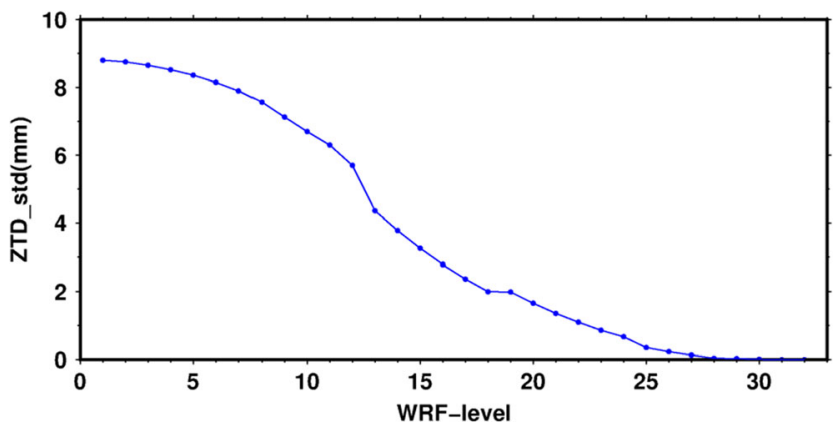

Fig. 3 The std of the ZTD in each level of the WRF model

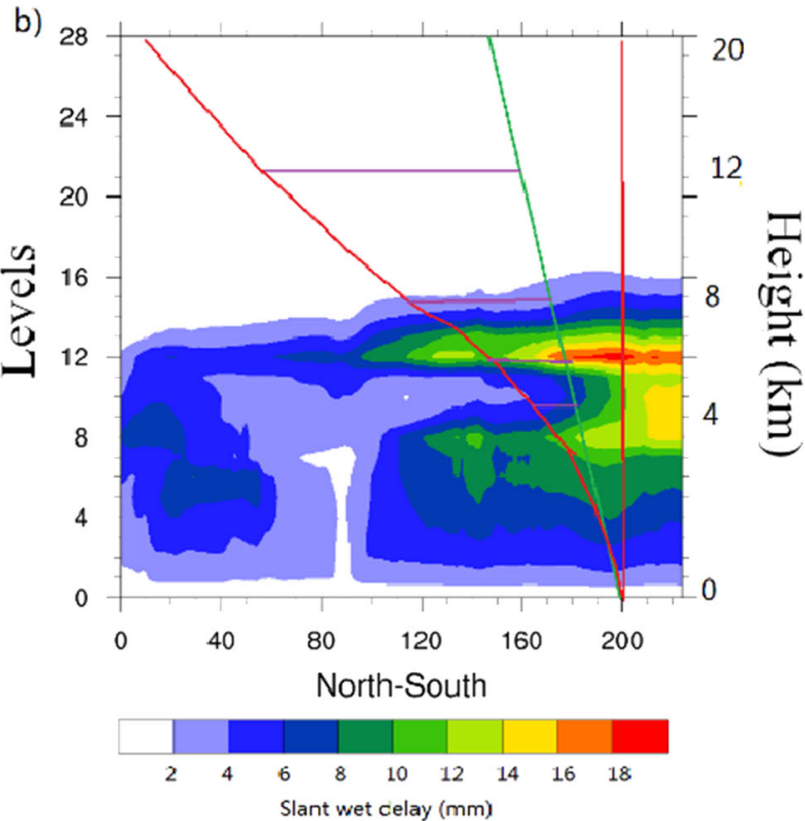

atmospheric delay in different levels (layers), and the purple horizontal line shows the difference between the 3D method and the simplification scheme

$L_{\mathrm{ZWD}}^{k}=\Pi^{-1} \times \mathrm{PWV}_{k}$

$\Pi^{-1}=10^{-6}\left(k_{2}^{\prime}+\frac{k_{3}}{47.2+0.8 T_{s}}\right) R_{w}$

where $R_{w}=461.495 \mathrm{~J} /(\mathrm{K} \cdot \mathrm{kg})$, and $T_{s}$ is the atmospheric temperature on the surface in $K$.

The hydrostatic delay at each level $\left(L_{\mathrm{ZHD}}^{k}\right)$ is computed by formula (7), which was improved by Elgered's research [40].

$L_{\mathrm{ZHD}}^{k}=2.2779 \times \frac{P_{s k}}{1-0.00266 \cos \left(2 \lambda_{k}\right)-0.00028 H_{k}}$

$P_{s k}, \lambda_{k}$, and $H_{k}$ are the total pressure in millibars, the latitude, and the height in kilometers, respectively, at the profile surface at each level.

And then, the vertical ZTD could be by adding the $L_{\mathrm{ZWD}}$ and $L_{\mathrm{ZHD}}$ at each level. Therefore, we can obtain the SLD by formula (8). Finally, integrate the SLD along the SAR signal trajectory and obtain more accurate values. It is noted that the $\operatorname{SLD}(k, i, j)$ could be SLD $(k-1, i+1, j)$ if the horizontal distance is more than the spatial resolution $1 \mathrm{~km}$ when integrating along the SAR signal path (Fig. 4).

$\mathrm{SLD}_{k}=\frac{\left(L_{\mathrm{ZWD}}^{k}+L_{\mathrm{ZHD}}^{k}\right)}{\cos \theta_{k}}$

The WRF resolution is $1 \mathrm{~km}$ while the SAR spatial resolution is meter level. To address this difference, we use kriging 
Fig. 4 Sketch map of the SAR signal propagating through the tropospheric atmosphere

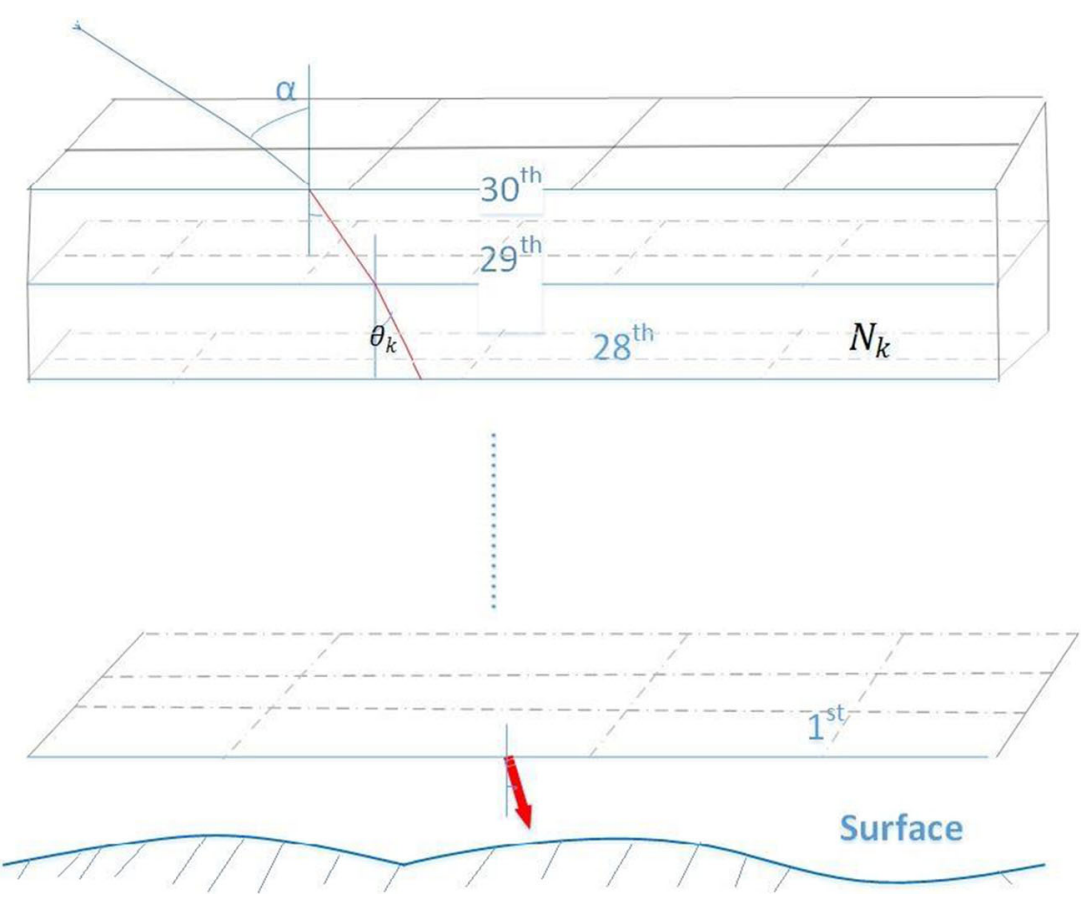

interpolation to interpolate the SLD simulated from the WRF model according to SAR images to eliminate the atmospheric effect on the InSAR deformation results.

\subsection{Interferometric Process and Atmospheric Correction}

Two SAR images can be interfered and generated into an interferogram pair, and the interferogram includes five-phase components (see Eq. (9)) [26].

$\Delta \varphi_{\text {InSAR }}=\Delta \varphi_{\text {orbit }}+\Delta \varphi_{\text {topo }}+\Delta \varphi_{\text {def }}+\Delta \varphi_{\text {atmo }}+\Delta \varphi_{\text {noise }}$

where $\Delta$ means the difference between the master image and the slave image. $\Delta \varphi_{\text {InSAR }}$ is the differential interferometric phase between two acquisition times, $\Delta \varphi_{\text {orbit }}$ is the phase resulting from the curved geometry of the Earth that is eliminated by using the precise orbit data, $\Delta \varphi_{\text {topo }}$ is the topographic phase which can be removed by subtracting a topographic phase simulated from a digital elevation model (DEM), $\Delta \varphi_{\text {noise }}$ is the phase noise resulting from the decorrelation of the InSAR signal because of land coverage which can be eliminated by filtering, $\Delta \varphi_{\text {def }}$ is the phase caused by surface deformation along the LOS direction, and $\Delta \varphi_{\text {atmo }}$ is the phase contribution of the atmosphere. After conventional D-InSAR processing using the software GMTSAR, only the surface deformation term $\Delta \varphi_{\text {def }}$ and the atmospheric contribution term $\Delta \varphi_{\text {atmo }}$ are left on the right side of Eq. (9).

The atmospheric phase delay is calculated by formula (10).

$\Delta \varphi_{\text {atmo }}=\frac{4 \pi}{\lambda} \times\left(\operatorname{SLD}_{m}-\operatorname{SLD}_{s}\right)$ where $\lambda$ is the wavelength of satellites. $\mathrm{SLD}_{m}$ and $\mathrm{SLD}_{s}$ represent the atmospheric delay at the acquisition time of the master image and slave image, respectively.

As for InSAR atmospheric correction, the atmospheric phase delay is then subtracted from the unwrapped interferograms to eliminate the atmospheric effects (see Eq. (11)).

$\Delta \varphi_{\mathrm{def}}=\Delta \varphi_{\mathrm{InSAR}}-\Delta \varphi_{\mathrm{atmo}}$

And the deformation result obtained from D-InSAR can be calculated utilizing Formula (12).

Deformation $=\frac{\lambda}{4 \pi} \times \Delta \varphi_{\text {def }}$

\section{Results and Discussion}

\subsection{Data and Study Area}

The study area is located around the Haiyuan Xian, in the western part of China. It is a topographically complex region dominated by multiple large, steep hills (see Fig. 5 (HY)). Atmospheric flow is strongly affected by this landscape fragmentation. Moreover, it is characterized by large variability of precipitation in summer because of its high and complex topography and its continental monsoon climate. The other study area is Taiwan island (see Fig. 5 (TW)), and it is surrounded by oceans and is considerably affected by the atmospheric water vapor. And more, its topography is complex 

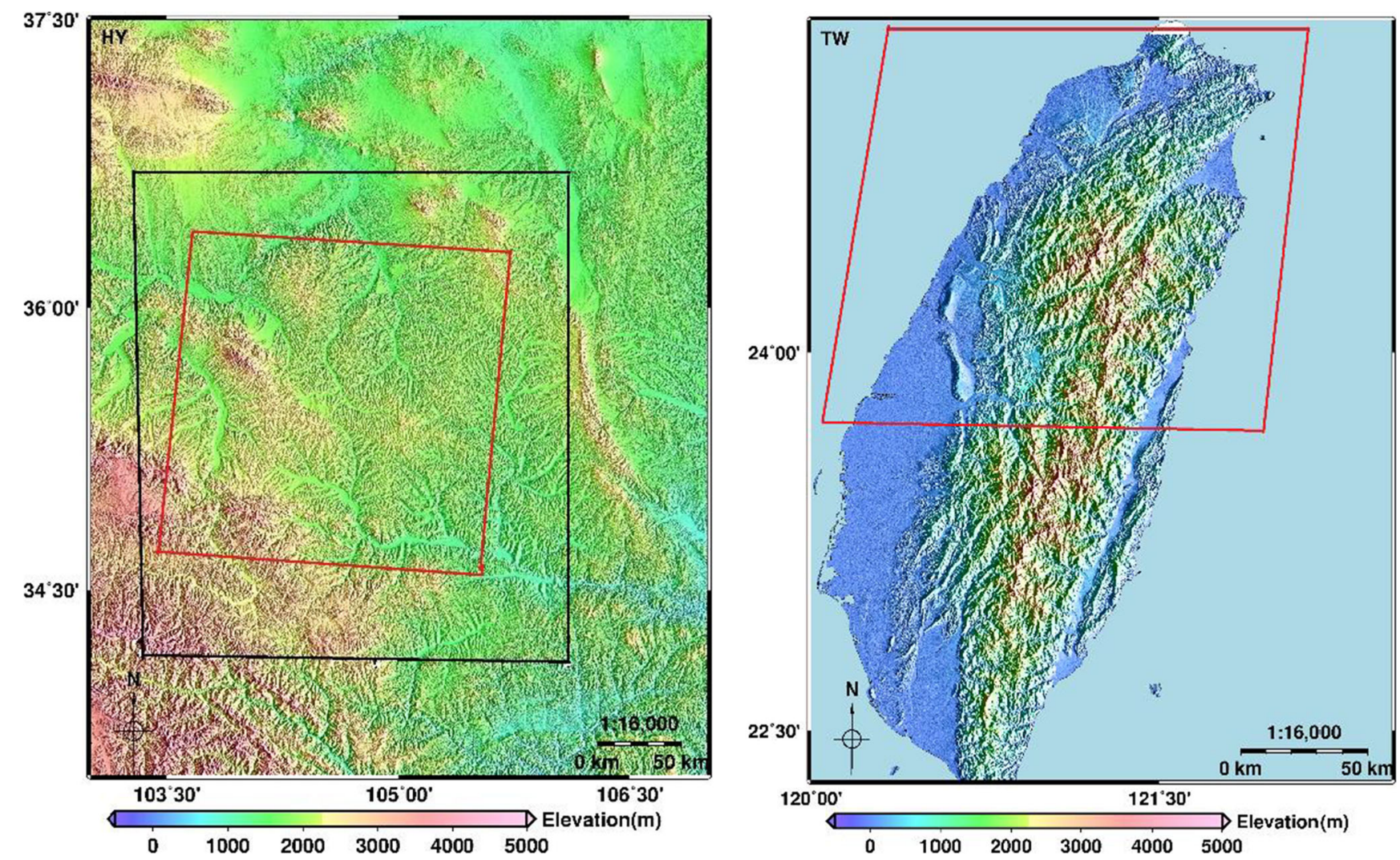

Fig. 5 DEM maps and the study area in the red rectangle utilized for the InSAR process and in the black rectangle used for SLD comparison in Haiyuan (HY) and the entire island of Taiwan (TW)

enough to represent different rough topographical terrain with a subtropical or tropical climate and vague seasons.

With respect to the SAR images, we utilized 12 Sentinel1A SAR images. Particularly, moderate rain occurred on February 28, 2016, and light rain occurred on November 12, 2019 , so the situation of both dates could represent the extreme weather conditions, taking sudden humidity changes into account. And these SAR images are formed 6 interference pairs, including 20190504-20190516, 20180801-20180813, 20191112-20191124, and 20200216-20200228 in Haiyuan and 20160228-20160323 and 20190904-20190928 in Taiwan. And as for the SAR images in Haiyuan and Taiwan, the range of the incidence angles is $30.8-46.13^{\circ}$ and $30.8-46^{\circ}$, respectively.

\subsection{Estimation of the SLD Obtained by Exact Profile Transformation}

According to Section 2, we computed the atmospheric slant delay at each level profile and implement the integral along the SAR signal trajectory.

For the six interference pairs mentioned above, the atmospheric slant delay is calculated and compared with those of the classic simplified method. Take the interference pairs of 201900504-20190516 in Haiyuan and
20160228-20160323 in Taiwan for example (see Figs. 6 and 7). The simulated incident angle uses a maximum of $60^{\circ}$, taking all of the current satellites' incidence angles into account (see the Appendix). It can be seen from the figures that the maximum difference between the two methods is more than $130 \mathrm{~mm}$ (see Fig. 7b-a). Theoretically, the classical simplified method ignores the complex atmospheric turbulence and horizontal gradient changes caused by the terrain changes. The method using three-dimensional data and polyline approximation is closer to the actual SAR signal propagation path and can better reflect the actual atmosphere delay effects on SAR signals.

To further quantify and evaluate the effectiveness of the proposed method, the proposed method is used to simulate the slant delay of different angles incidence, ranging 25$60^{\circ}$, and then was compared with those obtained by the classical simplified method and we use $35^{\circ}$ as the value of the average angle of incidence. The atmospheric delay differences between the two methods (the value obtained by the method proposed in this paper minus the value obtained by the classic simplified method) are averaged, std, and the range of the maximum and minimum values. The results are shown in Table 1. It can be seen that, in general, the average values of the difference between the two approaches are positive, that is, the atmospheric slant 


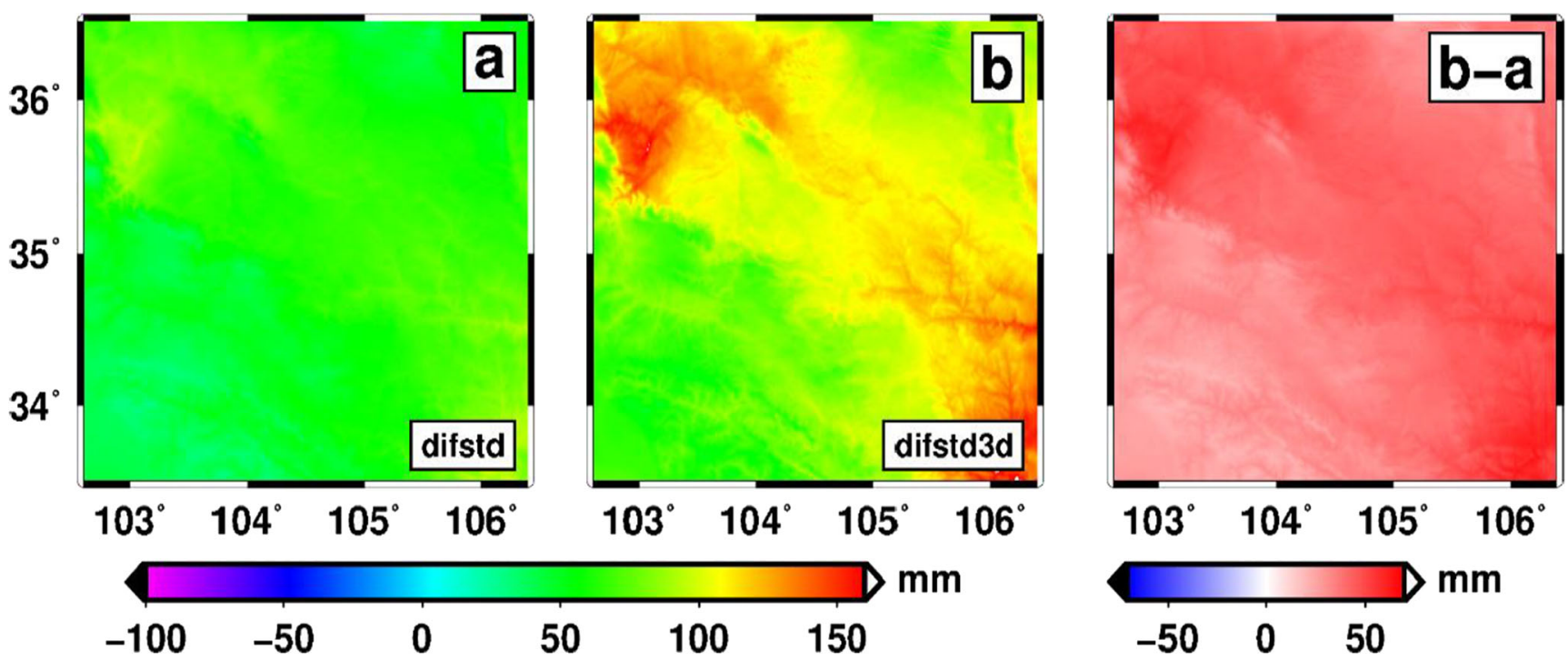

Fig. 6 The slant delay of the 20190504-20190516 SAR interferogram in Haiyuan and the difference between the two methods. Here, the maximum incidence angle is $60^{\circ}$, and the mean incidence angle is $35^{\circ}$

distance delays obtained by integrating the polyline values of each circle layer are greater than those obtained by using the average incidence angles.
Secondly, to clearly show the difference, the mean values of the discrepancies between SLDs obtained from the two methods at different local incidence angles are shown in
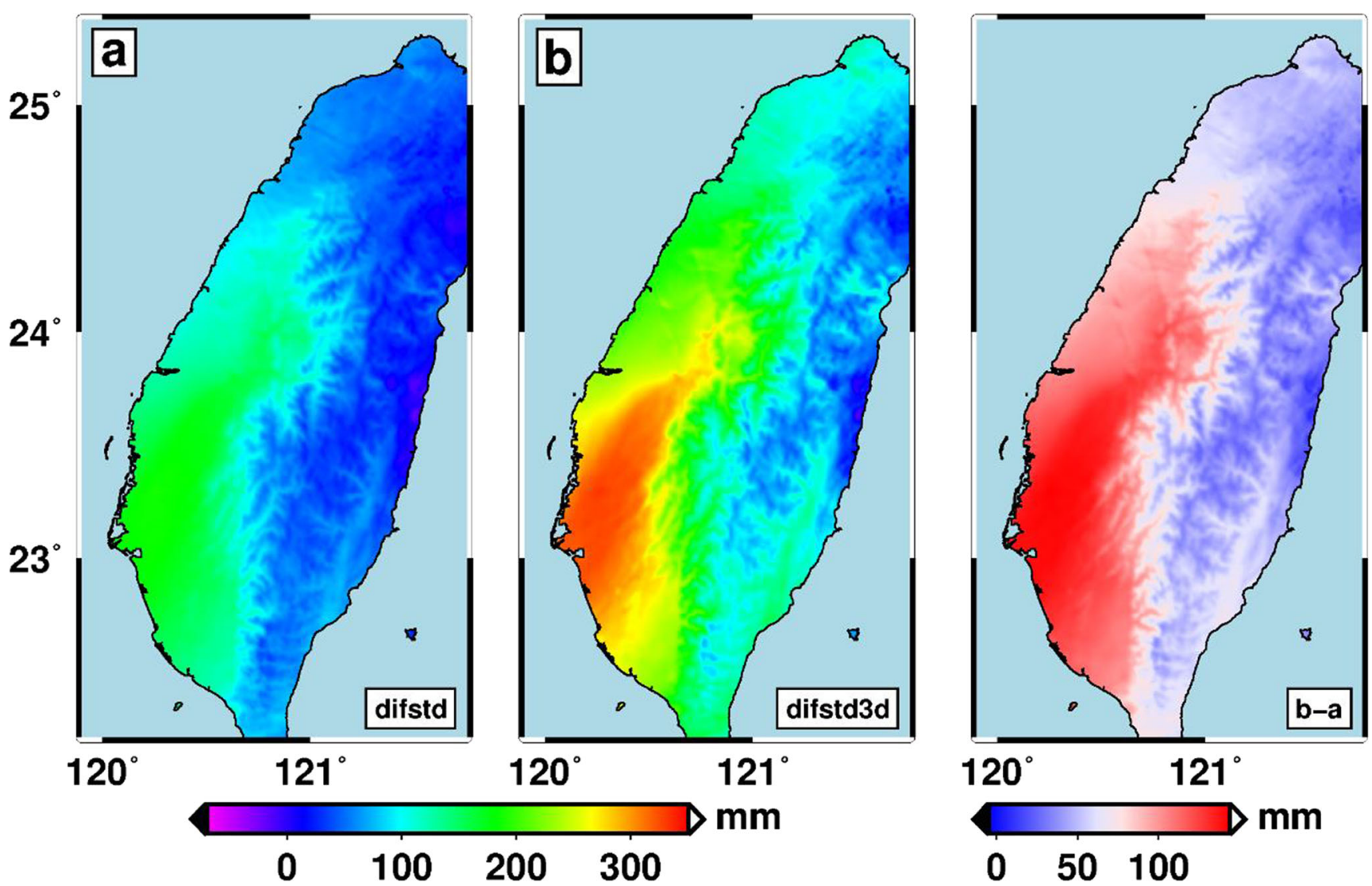

Fig. 7 The corresponding slant delay of the 20160228-20160323 SAR interferogram in Taiwan and the difference between the two methods. Here, the maximum incidence angle is $60^{\circ}$, and the mean incidence angle is $35^{\circ}$ 
Table 1 Differences of differential slant delay between the conventional simplified method and WRF 3D data using the different incidence angles and their mean, standard deviation, and range values

\begin{tabular}{|c|c|c|c|c|c|}
\hline Study areas & Ifgs & Incidence angle $\left(^{\circ}\right)$ & Mean $(\mathrm{mm})$ & std $(\mathrm{mm})$ & Range (mm) \\
\hline \multirow[t]{32}{*}{ Haiyuan } & \multirow[t]{8}{*}{ 20190504-0516 } & 25 & 6.9 & 3.2 & $4.5-15.2$ \\
\hline & & 30 & 12.3 & 4.1 & $5.1-19.1$ \\
\hline & & 35 & 17.4 & 7.3 & $7.5-25.3$ \\
\hline & & 40 & 20.8 & 6.2 & $9.4-28.8$ \\
\hline & & 45 & 21.0 & 8.6 & $10.3-30.7$ \\
\hline & & 50 & 27.0 & 8.4 & $8.5-37.3$ \\
\hline & & 55 & 30.0 & 9.0 & $15.6-50$ \\
\hline & & 60 & 39.5 & 13.2 & $24.2-60.2$ \\
\hline & \multirow[t]{8}{*}{$20180801-0813$} & 25 & 6.0 & 1.5 & $-4.0-10.2$ \\
\hline & & 30 & 7.9 & 2.1 & $2-12.6$ \\
\hline & & 35 & 15.0 & 2.8 & $1.6-20.4$ \\
\hline & & 40 & 21.0 & 4.5 & $3.8-37.5$ \\
\hline & & 45 & 24.9 & 5.3 & $7.1-41.0$ \\
\hline & & 50 & 24.0 & 5.0 & $4.2-38.3$ \\
\hline & & 55 & 28.4 & 6.3 & $3.7-40$ \\
\hline & & 60 & 37.0 & 8.7 & $6.2-59.8$ \\
\hline & \multirow[t]{8}{*}{$20191112-1124$} & 25 & 7.1 & 3.0 & $-0.3-15.2$ \\
\hline & & 30 & 10.0 & 3.4 & $1.5-20.6$ \\
\hline & & 35 & 17.3 & 4.1 & $3.7-28.5$ \\
\hline & & 40 & 19.7 & 4.9 & $2.8-40.1$ \\
\hline & & 45 & 20.0 & 5.6 & $4.3-45.6$ \\
\hline & & 50 & 22.4 & 7.3 & $3.6-48.0$ \\
\hline & & 55 & 25.0 & 7.0 & $8.3-43.1$ \\
\hline & & 60 & 32.0 & 8.2 & $5.2-50$ \\
\hline & \multirow[t]{8}{*}{ 20200216-0228 } & 25 & 6.9 & 2.5 & $-2.1-15.0$ \\
\hline & & 30 & 9.4 & 3.1 & $4.2-14.0$ \\
\hline & & 35 & 19.0 & 2.9 & $3.7-38.2$ \\
\hline & & 40 & 19.4 & 4.2 & $3.4-40.4$ \\
\hline & & 45 & 19.8 & 5.9 & $2.9-42.7$ \\
\hline & & 50 & 21.3 & 5.7 & $4.9-40.3$ \\
\hline & & 55 & 23.5 & 6.3 & $4.6-50.2$ \\
\hline & & 60 & 30.0 & 6.8 & $5.3-49.8$ \\
\hline \multirow[t]{16}{*}{ Taiwan } & \multirow[t]{8}{*}{$20160228-0323$} & 25 & 5.7 & 1.3 & $2.5-9.3$ \\
\hline & & 30 & 8.1 & 1.9 & $2.0-16.1$ \\
\hline & & 35 & 11.3 & 3.0 & $1.3-20.0$ \\
\hline & & 40 & 23.0 & 2.9 & $4.0-42.0$ \\
\hline & & 45 & 28.4 & 5.0 & $2.1-39.0$ \\
\hline & & 50 & 39.5 & 5.2 & $3.7-45.1$ \\
\hline & & 55 & 54.0 & 5.3 & $3.0-63.2$ \\
\hline & & 60 & 65.0 & 7.6 & $-17.2-97.8$ \\
\hline & \multirow[t]{8}{*}{ 201900904-0928 } & 25 & 10.2 & 3.0 & $1.2-23.4$ \\
\hline & & 30 & 13.3 & 2.8 & $3.1-25.0$ \\
\hline & & 35 & 25.0 & 4.0 & $8.3-42.0$ \\
\hline & & 40 & 36.4 & 6.1 & $6.3-53.1$ \\
\hline & & 45 & 36.9 & 7.0 & $1.4-49.2$ \\
\hline & & 50 & 40.3 & 7.3 & $5.1-60.0$ \\
\hline & & 55 & 48.0 & 8.1 & $3.9-63.7$ \\
\hline & & 60 & 62.6 & 8.5 & $10.8-100.3$ \\
\hline
\end{tabular}




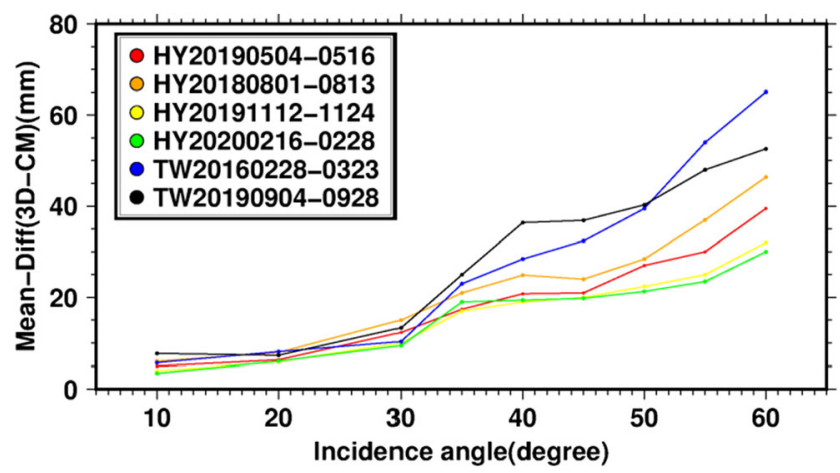

Fig. 8 Assessment of the discrepancies between SLDs obtained from the two methods at different local incidence angles

Fig. 8. It is illuminated that the difference between the two becomes larger as the incident angle becomes larger, and when the incidence angle is greater than $35^{\circ}$, a sharp increase phenomenon occurs. This phenomenon shows that when the incident angle is small, the influence of the simple method on the result is relatively small, but after the incident angle is greater than $35^{\circ}$, the error starts to increase sharply and cannot be ignored. Moreover, it is worth noting that the blue curve and black curve represent a larger difference than the others, which corresponds to the differential atmospheric phase delay of 20160228-0323 and 20190904-0916 in Taiwan, respectively. This is because it was a moderate rain on February 28, 2016, and a light rain on the September 4, 2019. For severely changing weather conditions, the results obtained by using $3 \mathrm{D}$ data to calculate the atmospheric slant range delay are more accurate and reliable.

Thirdly, the seasonal variability in Haiyuan (HY) can be found in Fig. 8 because the other three pairs (HY201905040516 (red line), HY20191112-1124 (yellow line), and 20200216-0228 (green line)) are smaller than the pair HY20180801-0813 (orange line). It is related to the dry climate of the Haiyuan, only more rain in July and August. This phenomenon is not obvious in Taiwan. We perceive that Taiwan island is significantly affected by the ocean. Hence, its atmospheric condition changes quickly especially regarding the water vapor. It could be demonstrated that both the atmospheric water vapor and seasonal climate have a noteworthy impact on the SLD discrepancies. And the conclusion is the same as the above that it is necessary to utilize the $3 \mathrm{D}$ data and profile transformation to compute more precise SLD values.

Fig. 9 a-d Deformation maps of D-InSAR of the 2019050420190516 with conventional simplified method atmospheric correction (CM-AC) and 3D scheme atmospheric correction (3D-AC) in Haiyuan
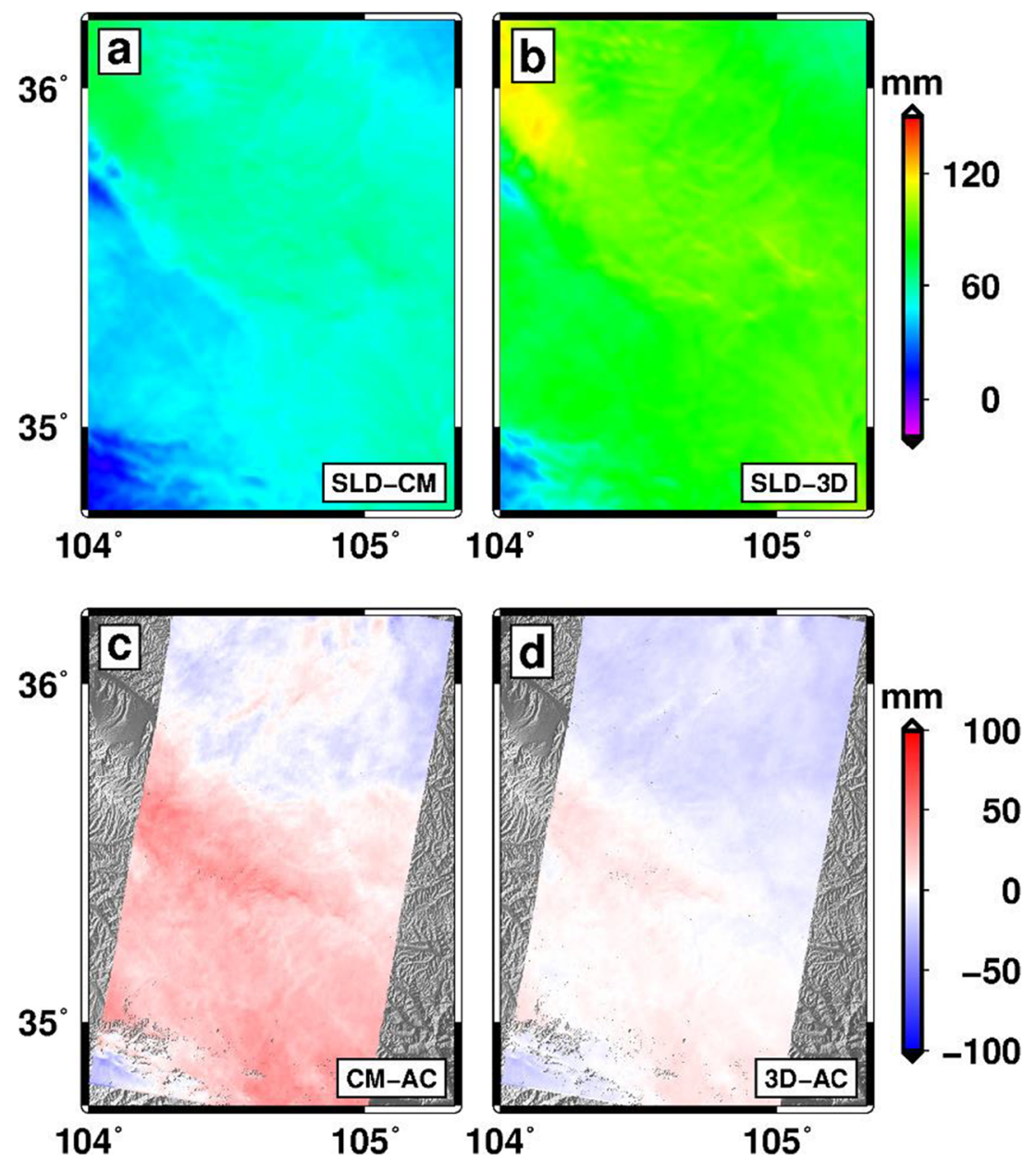


\subsection{Impact on the InSAR Atmospheric Correction}

Take the interferograms of 201900504-20190516 and 20180801-20180813 in Haiyuan and 20190904-0928 in Taiwan region for example. The deformation results from differential InSAR based on the WRF-SLD with the top incidence angle $46^{\circ}$ are shown in the Figs. 9, 10, and 11, respectively. Because of the very short period (12 days or 24 days) and no geological activity during the intervals, their InSAR surface deformations should be $0 \mathrm{~mm}$ in theory. All of the results illuminate that the surface deformation maps with $3 \mathrm{D}$ scheme atmospheric correction (3D$\mathrm{AC}$ ) are closer to $0 \mathrm{~mm}$ than with conventional simplified scheme atmospheric correction (CM-AC).

To evaluate the effectiveness of this approach, we assessed the error of the surface deformation from the D-InSAR results with the two different methods. The DInSAR error results of the interferograms (Ifgs) are displayed in Table 2, and it can be seen that the mean, standard deviation (std), and root mean square (RMS) errors after atmospheric correction with 3D slant total delay (3D-AC) are much smaller compared with those with $\mathrm{CM}$ atmospheric correction (CM-AC). This demonstrates that we simulated more accurate SLD and improve the InSAR surface deformation accuracy by using the level transformation.

\section{Conclusions}

3D data were utilized to obtain more accurate atmospheric total delay values along the SAR signal trajectory from the vertical ZTD at each WRF level. Firstly, the vertical ZTD and the refractivity index of each pixel at each level are calculated, and then at different levels, the vertical ZTD values are transformed into slant delay based on different refractivity. Ultimately, all of the slant delays at each level are integrated to obtain the atmospheric total delay. This approach makes the most of the 3D atmospheric refractivity index and solves the horizontal gradients between the two adjacent pixels of the WRF model. Meanwhile, it could reduce the errors caused by the atmospheric refraction in the horizontal and vertical directions. Compared with the conventional transformation scheme by dividing the cosine of the mean incidence angle of the satellite, considering the detailed atmospheric
Fig. 10 a-d Deformation maps of D-InSAR of the 2018080120180813 with conventional simplified method atmospheric correction (CM-AC) and 3D scheme atmospheric correction (3D-AC) in Haiyuan
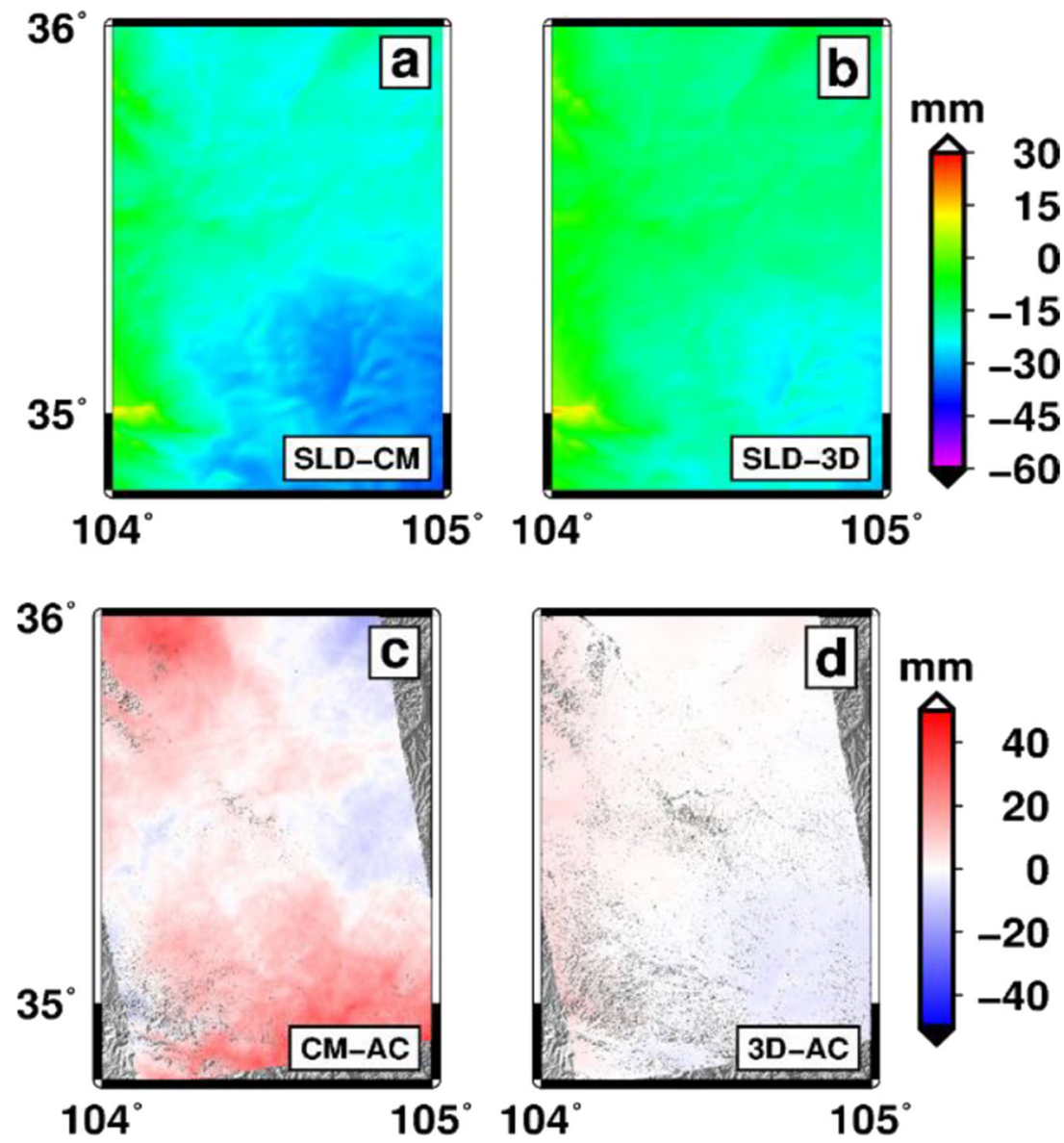
Fig. 11 a-d Deformation maps of D-InSAR of the 20190904-0928 with conventional simplified method atmospheric correction (CM-AC) and 3D scheme atmospheric correction (3D-AC) in Taiwan
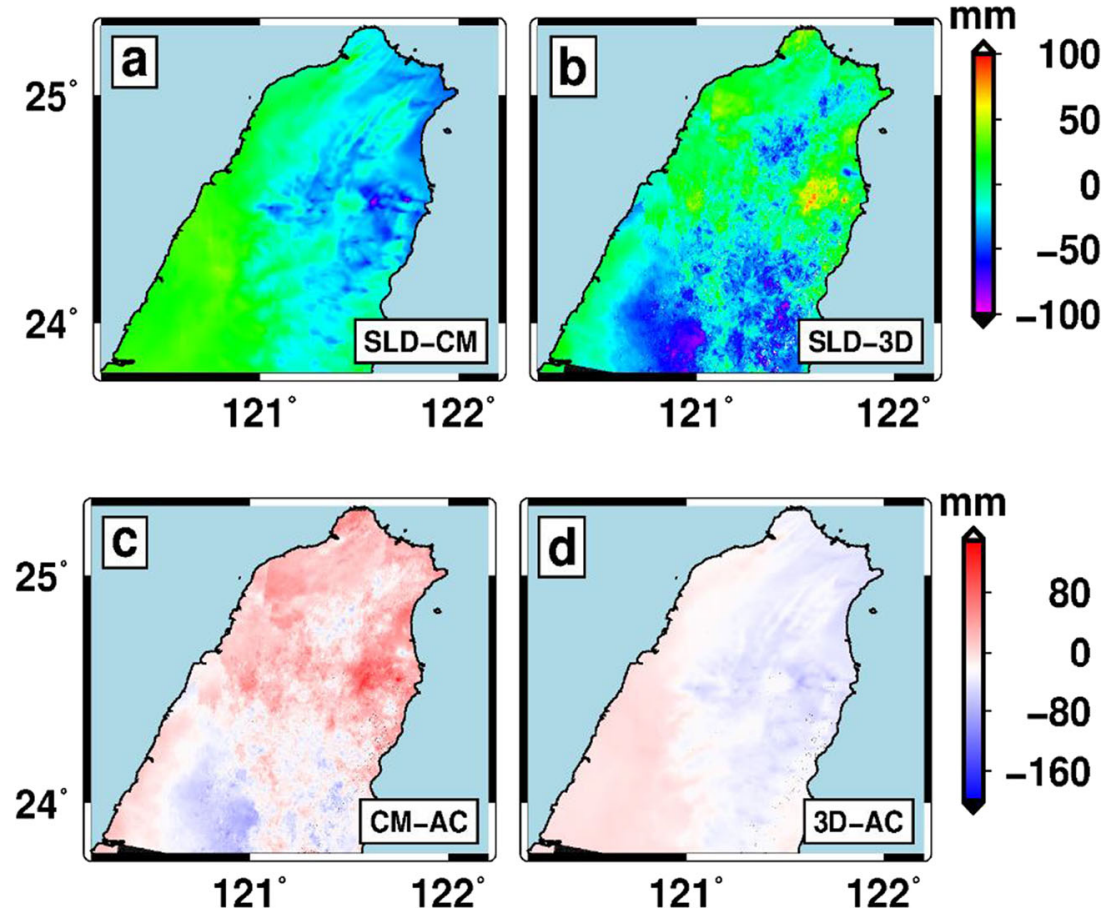

refraction index and integral the delays along the SAR signal trajectory can significantly improve the accuracy of the SLD and reduce the atmospheric impact on the surface deformation obtained from D-InSAR.

Moreover, we simulated slant delay at different incidence angles and found that it is necessary to use this proposed method instead of the traditional method to avoid errors and misinterpretation of the D-InSAR surface deformation when the incidence angle is larger than $35^{\circ}$. In terms of the evoke errors, the maximum error is about $40 \mathrm{~mm}$. Therefore, it is more suitable to utilize $3 \mathrm{D}$ data to simulate the atmospheric slant delay and mitigate the atmospheric effects on the DInSAR measurement.

As the development of numerical models is gradually improved, it is more imperative to use 3D atmospheric data to calculate SLD instead of the simplification scheme for the InSAR application. Integrating the delay along the line-ofsight between the ground point and the satellite is attainable and potential considerably. Applying numerical models into InSAR technology provides researchers with a reliable source of atmospheric data and an effective method in the field of geodetic technology.
Table 2 The mean, std, and RMS errors of D-InSAR deformation maps without and with atmospheric correction

\begin{tabular}{|c|c|c|c|c|}
\hline Ifgs, area & & Mean $(\mathrm{mm})$ & std $(\mathrm{mm})$ & $\mathrm{RMS}(\mathrm{mm})$ \\
\hline \multirow[t]{3}{*}{ 20190504-0516, Haiyuan } & Without AC & 90.7 & 31.6 & 32.4 \\
\hline & $\mathrm{CM}-\mathrm{AC}$ & 63.0 & 42.0 & 68.0 \\
\hline & 3D-AC & 13.0 & 10.6 & 22.9 \\
\hline \multirow[t]{3}{*}{ 20180801-0813, Haiyuan } & Without AC & -17.2 & 10.3 & 20.1 \\
\hline & $\mathrm{CM}-\mathrm{AC}$ & 2.6 & 9.5 & 9.8 \\
\hline & 3D-AC & 3.4 & 2.6 & 4.3 \\
\hline \multirow[t]{3}{*}{ 20190904-0928, Taiwan } & Without AC & 100.5 & 26.5 & 31.2 \\
\hline & CM-AC & 40.1 & 16.4 & 20.4 \\
\hline & $3 \mathrm{D}-\mathrm{AC}$ & -4.2 & 8.0 & 9.2 \\
\hline
\end{tabular}


Acknowledgments The NCEP GFS-FNL data are available via the NCAR Research Data Archive. The Sentinel-1A SAR images were downloaded from the European Space Agency. We used the Generic Mapping Tools (GMT) software to draw the figures and used GMTSAR to process the SAR images and complement the WRF-based atmospheric correction. We also would like to thank the highperformance computing platform of Peking University.

Funding This research was funded by the National Key Research and Development (R\&D) Program of China (No. 2017YFB0502703).

\section{Appendix}

Table 3 The incidence angles of the prevailing satellites

\begin{tabular}{|c|c|c|c|c|}
\hline Sensor & Valid time & $\begin{array}{l}\text { Band/ } \\
\text { wavelength }\end{array}$ & Operating mode & Incidence angle \\
\hline ERS-1 & 1991.07-2000.03 & $\mathrm{C} / 5.63$ & Strip map & $20 \sim 26^{\circ}$ \\
\hline JERS-1 & 1992.02-1998.10 & $\mathrm{L} / 23.5$ & Strip map & $35^{\circ}$ \\
\hline ERS-2 & 1995.04-2001.09 & $\mathrm{C} / 5.63$ & Strip map & $20 \sim 26^{\circ}$ \\
\hline Radarsat-1 & $1995.11-2013.03$ & $\mathrm{C} / 5.63$ & Standard & $20 \sim 49^{\circ}$ \\
\hline ENVISAT & 2002.03-2013.03 & $\mathrm{C} / 5.63$ & Image & $15 \sim 45^{\circ}$ \\
\hline ALOS-1 & 2006.01-2011.05 & $\mathrm{L} / 23.5$ & Strip map & $8 \sim 60^{\circ}$ \\
\hline \multirow[t]{4}{*}{ TerraSAR-X } & \multirow[t]{4}{*}{ 2007.06-now } & \multirow[t]{4}{*}{$\mathrm{X} / 3.12$} & H spotlight & $20 \sim 55^{\circ}$ \\
\hline & & & Spotlight & $20 \sim 55^{\circ}$ \\
\hline & & & Strip map & $20 \sim 45^{\circ}$ \\
\hline & & & ScanSAR & $20 \sim 45^{\circ}$ \\
\hline \multirow[t]{3}{*}{ COSMO-SkyMed } & \multirow[t]{3}{*}{ 2007.06-now } & \multirow[t]{3}{*}{$\mathrm{X} / 3.12$} & Spotlight & $25 \sim 50^{\circ}$ \\
\hline & & & Strip map & $25 \sim 50^{\circ}$ \\
\hline & & & ScanSAR & $25 \sim 50^{\circ}$ \\
\hline \multirow[t]{3}{*}{ Radarsat-2 } & \multirow[t]{3}{*}{ 2007.12-now } & \multirow[t]{3}{*}{$\mathrm{C} / 5.63$} & Spotlight & $20 \sim 49^{\circ}$ \\
\hline & & & Strip map & $20 \sim 60^{\circ}$ \\
\hline & & & ScanSAR & $20 \sim 49^{\circ}$ \\
\hline \multirow[t]{4}{*}{ TanDEM-X } & \multirow[t]{4}{*}{ 2010.06-now } & \multirow[t]{4}{*}{$\mathrm{X} / 3.12$} & H spotlight & $20 \sim 55^{\circ}$ \\
\hline & & & Spotlight & $20 \sim 55^{\circ}$ \\
\hline & & & Strip map & $20 \sim 45^{\circ}$ \\
\hline & & & ScanSAR & $20 \sim 45^{\circ}$ \\
\hline \multirow[t]{5}{*}{ Sentinel1-A } & \multirow[t]{5}{*}{ 2014.04-now } & \multirow[t]{5}{*}{$\mathrm{C} / 5.63$} & Strip map & $20 \sim 45^{\circ}$ \\
\hline & & & IW & $29 \sim 46^{\circ}$ \\
\hline & & & EW & $19 \sim 47^{\circ}$ \\
\hline & & & Ware mode & $22 \sim 35^{\circ}$ \\
\hline & & & & $35 \sim 38^{\circ}$ \\
\hline \multirow[t]{3}{*}{ ALOS-2 } & \multirow[t]{3}{*}{ 2014.05-now } & \multirow[t]{3}{*}{$\mathrm{L} / 23.5$} & Spotlight & $8 \sim 60^{\circ}$ \\
\hline & & & Strip map & $8 \sim 60^{\circ}$ \\
\hline & & & ScanSAR & $8 \sim 60^{\circ}$ \\
\hline \multirow[t]{5}{*}{ Sentinel1-B } & \multirow[t]{5}{*}{ 2016.04-now } & \multirow[t]{5}{*}{$\mathrm{C} / 5.63$} & Strip map & $20 \sim 45^{\circ}$ \\
\hline & & & IW & $29 \sim 46^{\circ}$ \\
\hline & & & EW & $19 \sim 47^{\circ}$ \\
\hline & & & Ware mode & $22 \sim 35^{\circ}$ \\
\hline & & & & $35 \sim 38^{\circ}$ \\
\hline \multirow[t]{7}{*}{ GF-3 } & \multirow[t]{7}{*}{ 2016.08-now } & \multirow[t]{7}{*}{$\mathrm{C} / 5.63$} & SL & $20 \sim 50^{\circ}$ \\
\hline & & & UFS & $20 \sim 50^{\circ}$ \\
\hline & & & FS & $19 \sim 50^{\circ}$ \\
\hline & & & WAVE & $20 \sim 41^{\circ}$ \\
\hline & & & GLOGAL & $17 \sim 53^{\circ}$ \\
\hline & & & EXTENDED & $10 \sim 20^{\circ}$ \\
\hline & & & & $50 \sim 60^{\circ}$ \\
\hline
\end{tabular}


Open Access This article is licensed under a Creative Commons Attribution 4.0 International License, which permits use, sharing, adaptation, distribution and reproduction in any medium or format, as long as you give appropriate credit to the original author(s) and the source, provide a link to the Creative Commons licence, and indicate if changes were made. The images or other third party material in this article are included in the article's Creative Commons licence, unless indicated otherwise in a credit line to the material. If material is not included in the article's Creative Commons licence and your intended use is not permitted by statutory regulation or exceeds the permitted use, you will need to obtain permission directly from the copyright holder. To view a copy of this licence, visit http://creativecommons.org/licenses/by/4.0/.

\section{References}

1. Ryder I, Parsons B, Wright TJ, Funning GJ (2007) Post-seismic motion following the 1997 Manyi (Tibet) earthquake: InSAR observations and modelling. Geophys J Int 169:1009-1027. https:// doi.org/10.1111/j.1365-246X.2006.03312.x

2. Wei M, Sandwell D, Fialko Y, Bilham R (2011) Slip on faults in the Imperial Valley triggered by the 4 April 2010 Mw 7.2 El MayorCucapah earthquake revealed by InSAR. Geophys. Res. Lett. 38: L01308. https://doi.org/10.1029/2010GL045235

3. Wright TJ, Lu Z, Wicks C (2003) Source model for the Mw 6.7, 23 October 2002, Nenana Mountain Earthquake (Alaska) from InSAR. Geophys Res Lett 30:1974. https://doi.org/10.1029/ 2003GL01801418

4. Xiong W, Chen W, Zhao B et al (2019) Insight into the 2016 Menyuan Mw 5.9 earthquake with InSAR: a blind reverse event promoted by historical earthquakes. Pure Appl. Geophys 176:577591. https://doi.org/10.1007/s00024-018-2000-0

5. González PJ, Bagnardi M, Hooper AJ et al (2015) The 2014-2015 eruption of Fogo volcano: geodetic modeling of Sentinel-1 TOPS interferometry. Geophys Res Lett 42:9239-9246. https://doi.org/ 10.1002/2015GL066003

6. Jung J, Kim DJ, Park SE (2014) Correction of atmospheric phase screen in time series InSAR using WRF model for monitoring volcanic activities. IEEE Trans Geosci Remote Sens 52(5):26782689. https://doi.org/10.1109/TGRS.2013.2264532

7. Schaefer LN, Lu Z, Oommen T (2015) Dramatic volcanic instability revealed by InSAR. Geology 43(8):743-746. https://doi.org/10. 1130/G36678.1

8. Wang L, Li N, Zhang X et al (2018) Full parameters inversion model for mining subsidence prediction using simulated annealing based on single line of sight D-InSAR. Environ Earth Sci 77:161. https://doi.org/10.1007/s12665-018-7355-0

9. Yang ZF, Li ZW, Zhu J et al (2017) An extension of the InSARbased probability integral method and its application for predicting 3-D mining-induced displacements under different extraction conditions. IEEE Transactions on Geoscience and Remote Sensing 55(7):3835-3845. https://doi.org/10.1109/TGRS.2017.2682192

10. Kutoglu HS, Kemaldere H, Deguchı T et al (2014) Discovering a pull-apart basin using InSAR in Bursa, Turkey. Nat Hazards 71: 871-880. https://doi.org/10.1007/s11069-013-0938-x

11. Dang VK, Doubre C, Weber C et al (2013) Recent land subsidence caused by the rapid urban development in the Hanoi region (Vietnam) using ALOS InSAR data. Natural Hazards and Earth System Sciences Discussions 1(6):6155-6197. https://doi.org/10. 5194/nhessd-1-6155-2013

12. Fruneau B, Sarti F (2000) Detection of ground subsidence in the city of Paris using radar interferometry: isolation of deformation from atmospheric artifacts using correlation. Geophys Res Lett 27(24):3981-3984. https://doi.org/10.1029/2000GL008489

13. Lu Y, Ke C, Jiang H et al (2019) Monitoring urban land surface deformation (2004-2010) from InSAR, groundwater and levelling data: a case study of Changzhou city, China. J Earth Syst Sci 128: 159. https://doi.org/10.1007/s12040-019-1173-y

14. Qu FF, Lu Z, Zhang Q et al (2015) Mapping ground deformation over Houston-Galveston, Texas using multi-temporal InSAR. Remote Sensing of Environment 169:290-306. https://doi.org/10. 1016/j.rse.2015.08.027

15. Hanssen R (2001) Radar interferometry: data interpretation and error analysis, vol 2, 1st edn. Kluwer Academic Publishers, Dordrecht, pp 130-154

16. Zebker HA, Rosen PA, Hensley S (1997) Atmospheric effects in the interferometric synthetic aperture radar surface deformation and topographic maps. J Geophys Res 102(B4):7547-7563. https://doi. org/10.1029/96JB03804

17. Chen F, Lin H, Cheng S (2013) Principles, methods and applications of spaceborne radar interferometry and time series analysis. Science Press, Beijing

18. Foster J et al (2006) Mitigating atmospheric noise for InSAR using a high-resolution weather model. Geophys. Res. Lett 33:L16304. https://doi.org/10.1029/2006GL026781

19. Li ZH, Muller JP, Cross P (2003) Comparison of precipitable water vapor derived from radiosonde, GPS, and moderate-resolution imaging spectroradiometer measurements. J Geophys Res 108(D20): 4651. https://doi.org/10.1029/2003JD003372

20. Li ZH, Muller JP, Cross P et al (2006a) Assessment of the potential of MERIS near-infrared water vapour products to correct ASAR interferometric measurements. Int J Remote Sens 27(2):349-365. https://doi.org/10.1080/01431160500307342

21. Li Z et al (2007) Assessment of the potential of MERIS nearinfrared water vapor products to correct ASAR interferometric measurements. Int J Remote Sens 27(2):349-365. https://doi.org/ 10.1080/01431160500307342

22. Li ZH, Fielding EJ, Cross P et al (2006b) Interferometric synthetic aperture radar atmospheric correction: GPS topography-dependent turbulence model. Journal of Geophysical Research: Solid Earth 111(B2). https://doi.org/10.1029/2005JB003711

23. Webley PW et al (2002) Atmospheric water vapour correction to InSAR surface motion measurements on mountains: results from a dense GPS network on Mount Etna. Phys Chem Earth Parts A/B/C 27(4):363-370. https://doi.org/10.1016/S1474-7065(02)00013-X

24. Yu C, Li Z, Penna NT et al (2018) Generic atmospheric correction model for interferometric synthetic aperture radar observations. Journal of Geophysical Research: Solid Earth. https://doi.org/10. 1029/2017JB015305

25. Jolivet R et al (2011) Systematic InSAR tropospheric phase delay corrections from global meteorological reanalysis data. Geophys Res Lett 38:L17311. https://doi.org/10.1029/2011GL048757

26. Yun Y, Zeng Q, Green BW (2015) Mitigating atmospheric effects in InSAR measurements through high-resolution data assimilation and numerical simulations with a weather prediction model. Int $\mathrm{J}$ Remote Sens 36(8):2129-2147. https://doi.org/10.1080/01431161. 2015.1034894

27. Doin MP et al (2009) Corrections of stratified tropospheric delays in SAR interferometry: validation with global atmospheric models. J Appl Geophys 69(1):35-50. https://doi.org/10.1016/j.jappgeo. 2009.03.010

28. Hobiger T, Kinoshita Y, Shimizu S et al (2010) On the importance of accurately ray-traced troposphere corrections for Interferometric SAR data. J Geod 84:537. https://doi.org/10.1007/s00190-0100393-3

29. Perissin D, Pichelli E, Ferretti R et al (2010) Mitigation of atmospheric water-vapour effects on spaceborne interferometric SAR 
imaging through the MM5 numerical model. Piers Online 6(6): 262-266

30. Puysségur B, Michel R, Avouac JP (2007) Tropospheric phase delay in interferometric synthetic aperture radar estimated from meteorological model and multispectral imagery. J Geophys Res 112:B05419. https://doi.org/10.1029/2006JB004352

31. Bekaert D, Walters R, Wright $T$ et al (2015) Statistical comparison of InSAR tropospheric correction techniques. Remote Sens Environ 170:40-47. https://doi.org/10.1016/j.rse.2015.08.035

32. Fornaro G et al (2015) Assimilation of GPS-derived atmospheric propagation delay in DInSAR data processing. IEEE J Sel Top Appl 8(2):874-799

33. $\mathrm{Li} \mathrm{ZH} \mathrm{(2005)} \mathrm{Correction} \mathrm{of} \mathrm{atmospheric} \mathrm{water} \mathrm{vapour} \mathrm{effects} \mathrm{on}$ repeat pass SAR interferometry using GPS, MODIS and MERIS data. Dissertation, University College London

34. Nico G, Tome R, João P. S. Catalão, et al. (2011) On the use of the WRF model to mitigate tropospheric phase delay effects in SAR interferograms. IEEE Trans Geosci Remote Sens 49(12):49704976. https://doi.org/10.1109/TGRS.2011.2157511

35. Lagler K, Schindelegger M, Böhm J, Krásná H, Nilsson T (2013) GPT2: empirical slant delay model for radio space geodetic techniques. Geophys. Res. Lett. 40:1069-1073. https://doi.org/10.1002/ grl.50288
36. Yuan Y, Holden L, Kealy A et al (2019) Assessment of forecast Vienna Mapping Function 1 for real-time tropospheric delay modeling in GNSS. J Geod 93:1501-1514. https://doi.org/10. 1007/s00190-019-01263-9

37. Hobiger T, Ichikawa R, Koyama Y, Kondo T (2008) Fast and accurate ray-tracing algorithms for real-time space geodetic applications using numerical weather models. J Geophys Res 113: D20302. https://doi.org/10.1029/2008JD010503

38. Smith EK, Weintraub S (1953) The constants in the equation for atmospheric refractive index at radio frequencies. Proc IRE 41(8): 1035-1037

39. Bevis M et al (1992) GPS meteorology: remote sensing of atmospheric water vapor using the global positioning system. J Geophys Res 97(D14):15787-15801. https://doi.org/10.1029/92JD01517

40. Elgered, G., Davis, J. L., Herring, T. A., and Shapiro, I. I. (1991), Geodesy by radio interferometry: Water vapor radiometry for estimation of the wet delay, J. Geophys. Res., 96( B4), 6541- 6555, https://doi.org/10.1029/90JB00834.

Publisher's Note Springer Nature remains neutral with regard to jurisdictional claims in published maps and institutional affiliations. 